\title{
Research on Xiaomi's Internationalized Business Model
}

\author{
Ruyi Wei, Qiong Long* \\ Beijing Institute of Fashion Technology, Beijing, China \\ Email: *sxylqiong@bift.edu.cn
}

How to cite this paper: Wei, R. Y., \& Long, Q. (2021). Research on Xiaomi's Internationalized Business Model. Open Journal of Business and Management, 9, 1050-1063. https://doi.org/10.4236/ojbm.2021.93056

Received: March 2, 2021

Accepted: May 4, 2021

Published: May 7, 2021

Copyright (c) 2021 by author(s) and Scientific Research Publishing Inc. This work is licensed under the Creative Commons Attribution International License (CC BY 4.0).

http://creativecommons.org/licenses/by/4.0/ (c) (i) Open Access

\begin{abstract}
As a young technology-based company, Xiaomi's international business continues to develop and grow. This article studies the international business model of Xiaomi. Through the analysis of the motivations of Xiaomi's internationalization, this paper obtains the reasons for Xiaomi's entry into the international market. We also study the choice of target market, the mode of entering the target market and the marketing strategy in the process of Xiaomi's internationalization. Finally, it summarizes Xiaomi's internationalization experience and puts forward enlightenment.
\end{abstract}

\section{Keywords}

Xiaomi Company, International Motivation, International Market Choice, International Business Model

\section{Introduction}

Smartphones emerged in 2007. At the beginning of their development, Apple's mobile phones were the representative. By the time Apple's fourth-generation mobile phones iPhone 4 and iPhone $4 \mathrm{~S}$, smartphones became popular all over the world. Driven by Apple's smartphones, smartphone manufacturers around the world begun to imitate, and various brands such as LG, Samsung, HTC, ZTE, Huawei, and Lenovo emerged.

Xiaomi was officially established in April 2010. It is an Internet company with mobile phones, smart hardware and IoT platforms as its core. At this time, smartphones are already relatively mature. Xiaomi's LOGO is an "MI" shape, which is the abbreviation of Mobile Internet, which means that Xiaomi is a mobile Internet company. In addition, Xiaomi's reversed logo is a Chinese 
word “心” missing a dot stroke, which means that Xiaomi wants to save users a little bit of worry. When it established, Xiaomi slogan "Born for fever", perfectly integrated the two characteristics of "low price" and "high cost performance" and deeply imprinted them in the minds of consumers; at the same time, it proposed "let everyone enjoy the fun of science and technology" mission. From 2010 to 2013, Xiaomi has been developing in the domestic market; from 2014, Xiaomi began to enter the international market and opened up overseas markets. After 2014, with the rapid development of Xiaomi in overseas markets, the income of overseas markets has increased year by year. By 2018, overseas income has reached $40 \%$ of total income. Its mission has been revised to "Let everyone in the world enjoy the beautiful life brought by technology". "Everyone" emphasizes the whole world, and the number of languages on Xiaomi's official website has reached thirty-one, which shows that Xiaomi attaches great importance to overseas markets.

Xiaomi has been established for only 11 years, but it has achieved great achievements in the market. On July 9, 2018, Xiaomi was officially listed on the Hong Kong Main Board. In the second quarter of 2019, Xiaomi's revenue reached RMB 52.9 billion, and it was listed on the Fortune 500, ranking 468. It took only 9 years to become the youngest Fortune 500; in overseas markets, only in India, there are more than 6000 stores in three forms, including more than $1790 \mathrm{Mi}$ Store stores focusing on second-tier cities and rural areas. In Europe, Xiaomi has opened more than 100 offline stores. As of the end of 2019, Xiaomi has entered more than 90 countries and regions around the world, and entered the top five markets in 42 countries and regions, with overseas market revenue reaching $48.7 \%$ of total revenue.

\section{Motivation and Current Situation of Xiaomi's Internationalization}

\subsection{Motivation of Xiaomi's Internationalization}

\subsubsection{Fierce Competition in the Domestic Market}

China's domestic smartphone market is the world's largest smartphone market, but after the rapid growth in the past few years, the growth rate of smartphone sales has slowed down and almost stagnant. According to Canalys report, the growth rate of smartphones in China has been declining since 2014. The average growth rate of smartphone sales in China from 2014 to 2018 was less than $10 \%$. Compared with the previous growth of more than $100 \%$, the growth rate has slowed down significantly. In 2017 , domestic smartphones fell by $4 \%$ compared with 2016, showing negative growth for the first time. China's mobile phone sales showed a sharp decline, which means that the domestic mobile phone market has become saturated. At the same time, the competitiveness of domestic enterprises has increased, and the "price war" among major mobile phone brands has gradually reduced the profitability of enterprises.

Before 2014, the Chinese mobile phone market was in the transition period from functional phones to smartphones. During this period, Xiaomi relied on 
cost-effective products to gain the favor of many domestic mobile phone users, sales of Xiaomi smartphones grew rapidly. However, in the big environment of China's smartphone market becoming saturated at that time, the survival space of small and medium-sized mobile phones was getting smaller and smaller, and their competitiveness could not be guaranteed. Therefore, it is very necessary for Xiaomi to carry out international operations.

\subsubsection{The Foreign Market Is Broader}

Due to the imbalance of global economic development, in some developing countries, the penetration rate of smartphones is generally low, sso it has great development space and potential. As the second most populous country in the world, India has a huge potential market. According to data released by Canalys, the penetration rate of smartphones in India was 17\% in 2015. The average annual sale of smartphones in the Indian market from 2014 to 2018 was 112 million, and the growth rate was $10 \%$. Even so, by 2018 , India's smartphone penetration rate is only $22 \%$, and it still has great potential. The rapid development trend of Indian smartphone market is very similar to the Chinese smartphone market in previous years, which makes domestic smartphone companies see new opportunities. In addition to the extreme attention paid to the Indian market, other countries and regions with rapid economic development, such as Southeast Asia and Latin American countries, are also the markets that domestically produced smartphones focus on. Most of the market share of these emerging smartphone markets is occupied by low-end smartphones, which will help Xiaomi to sell its cost-effective products. Therefore, these emerging foreign mobile phone markets with great development potential provide opportunities for Xiaomi to carry out national operations.

\subsubsection{Improve the International Competitiveness of Enterprises}

In the context of the globalization of the world economy, if an enterprise is complacent and only develops the domestic market, it will surely be eliminated in the competition at home and abroad. It is precisely because of the openness and competitiveness of the international market that companies are forced to continuously update technology and improve management systems to form their own competitive advantages. Only when domestic enterprises fully integrate everything they own, use their capital cost advantages to speed up the process of internationalization, and dare to compete in an open market, can they improve their core competitiveness. If Xiaomi can succeed in the international market, it will not only drive the growth of volume, expand the production scale of products, and achieve scale effects, but also obtain smartphone parts at a lower cost, increase its bargaining power with suppliers and expand Xiaomi's brand influence in the international market. The most important thing is that after opening up the national market, Xiaomi can continuously accumulate experience in nationalized operations and improve its international competitiveness. 


\subsection{The Current Situation of Xiaomi's Internationalization}

In the global market, Xiaomi shipped 57.7 million mobile phones in 2014, with a global market share of $4.4 \%$; in 2015, it shipped 70.8 million units with a global market share of $4.9 \%$, an increase of $22.8 \%$ over the previous year. In 2016, it was a difficult year for Xiaomi. The shipment volume is only 53 million units, which is very different from the 80 million expected. In 2017, Xiaomi grew against the trend, with shipments of 92.4 million units and a global market share of $6.3 \%$, year-on-year growth of $74.5 \%$ compared with the previous year. With Xiaomi's continuous expansion in overseas markets, in 2018, Xiaomi's shipments exceeded 100 million, reaching 119.1 million units, and its global market share rose to $8.7 \%$, with a year-on-year increase of $74.5 \%$; in 2019 , Xiaomi continued to expand its overseas market, with the annual shipment volume reaching 125.6 million units, and the market share reached 9.2\%, as shown in Figure 1.

In the smartphone industry, in 2016, Xiaomi was still not on the list; in 2017, it surpassed VIVO and other companies, ranking fifth; in 2018, it continued to surpass OPPO, ranking fourth only to Samsung, Huawei and Apple in the world; in 2019, it continued to maintain its fourth position and expand its market share, as shown in Table 1.

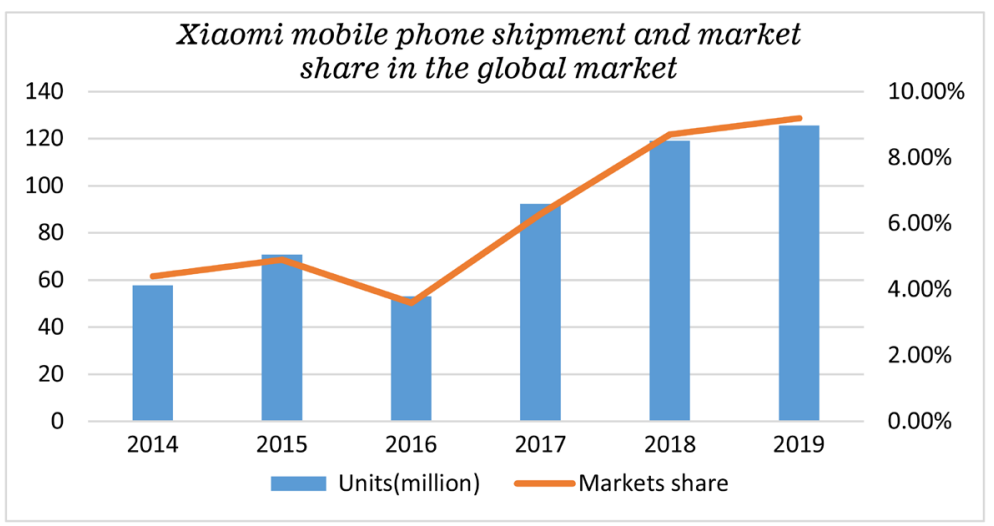

Data Source: IDC.

Figure 1. Shipment and market share of Xiaomi mobile phones in the global market.

Table 1. Statistics of market share of top five smartphone companies.

\begin{tabular}{|c|c|c|c|c|c|c|c|}
\hline \multicolumn{2}{|c|}{2016} & \multicolumn{2}{|c|}{2017} & \multicolumn{2}{|c|}{2018} & \multicolumn{2}{|c|}{2019} \\
\hline Company & Market Share & Company & Market Share & Company & Market Share & Company & Market Share \\
\hline 1. Samsung & $21.2 \%$ & 1.Samsung & $21.7 \%$ & 1. Samsung & $20.8 \%$ & 1. Samsung & $21.6 \%$ \\
\hline 2. Apple & $14.6 \%$ & 2.Apple & $14.7 \%$ & 2. Apple & $14.9 \%$ & 2. Huawei & $17.6 \%$ \\
\hline 3. Huawei & $9.5 \%$ & 3.Huawei & $10.5 \%$ & 3. Huawei & $14.7 \%$ & 3. Apple & $13.9 \%$ \\
\hline 4. OPPO & $6.8 \%$ & 4.OPPO & $7.6 \%$ & 4. Xiaomi & $8.7 \%$ & 4. Xiaomi & $9.2 \%$ \\
\hline 5. VIVO & $5.3 \%$ & 5.Xiaomi & $6.3 \%$ & 5. OPPO & $8.1 \%$ & 5. OPPO & $8.3 \%$ \\
\hline Others & $42.6 \%$ & Others & $39.2 \%$ & Others & $32.8 \%$ & Others & $29.4 \%$ \\
\hline Total & $100 \%$ & Total & $100 \%$ & Total & $100 \%$ & Total & $100 \%$ \\
\hline
\end{tabular}

Data Source: IDC. 
Table 2. Xiaomi's overseas market revenue and proportion.

\begin{tabular}{cccccc}
\hline & $\mathbf{2 0 1 5}$ & $\mathbf{2 0 1 6}$ & $\mathbf{2 0 1 7}$ & $\mathbf{2 0 1 8}$ & $\mathbf{2 0 1 9}$ \\
\hline $\begin{array}{c}\text { International market } \\
\text { revenue (billion yuan) }\end{array}$ & 4.05 & 9.15 & 32.08 & 70.00 & 91.20 \\
$\begin{array}{c}\text { Year-on-year growth } \\
\text { Proportion of total revenue }\end{array}$ & $6.1 \%$ & $13.4 \%$ & $28 \%$ & $40 \%$ & $44.3 \%$ \\
\hline
\end{tabular}

Data source: Xiaomi's prospectus \& Xiaomi's annual report.

Overseas market revenue also reflects the deepening of Xiaomi's internationalization. Since 2015, Xiaomi's overseas market revenue has continued to increase, with a year-on-year growth of $250.4 \%$ in 2017 , and a rapid growth rate of $118.1 \%$ in 2018. Revenue accounted for $40 \%$ of total revenue in 2018 and $44.3 \%$ in 2019, as shown in Table 2.

\section{Xiaomi's Internationalization Target Market Selection and Development Achievements}

\subsection{Initial Stage-Indian Market (2014-2016)}

Xiaomi started to internationalize in early 2014 and enter the international market. In April 2014, Xiaomi planned to enter India, Russia, Brazil and other 10 countries within a year, spanning Asia, Europe and the Americas. But the actual progress was greatly reduced, it did not enter Brazil until July 2015. Due to the high tariff problem in the Brazilian market, Xiaomi withdrew from Brazil in less than a year (Zhang, 2016). In 2016, Xiaomi's business suffered a setback, the actual shipment volume was only 53 million units, which was very different from the expectation of 80 million units. Xiaomi made a profound reflection, believing that "globalization cannot be radical, and a long-term plan for 10 or 20 years is needed. Do each market one by one", so he focused on India and began to develop Indian market. The main reasons for choosing India as the key development market are as follows:

1) India's Internet ecosystem is mature

If Xiaomi wants their mobile phone to enter another country, the primary factor is that the mobile phone can be used normally in this country. Compared with countries and regions such as Africa and Latin America, India has relatively complete infrastructure construction, with comprehensive coverage of base stations and signal towers, which can ensure the normal operation of mobile phones.

Secondly, Indian operators are also an important factor in boosting Xiaomi's sales in India. With many Indian operators and low 3G/4G charges, more and more Indian bottom-level Internet users who did not dare to luxury mobile Internet can easily access digital information. With the popularization of $4 \mathrm{G}$ networks, smartphones are also making profits.

In addition, the maturity of the Indian Internet ecosystem allows Xiaomi to 
easily replicate its MIUI, hardware ecological chain, and strategic investment approach in India.

2) Huge crowd of Indian mobile phone consumers

India has a huge population, and the huge population base has brought about a tide of smartphone replacements, and the number of Indian mobile phone consumers is also huge. According to the latest figures from the Telecommunications Authority of India, as of May 2017, the total number of mobile phone users in India reached 1.181 billion. India surpasses the United States to become the world's second largest smartphone market after China.

3) Relatively weak competition in the Indian market

At the beginning of 2014, the main smartphone sellers in India were Samsung and some local companies. OPPO and VIVO have just conducted a round of dealer adjustments, and the channels have not been sorted out; Huawei has not entered India due to brand positioning considerations. Compared with the domestic market, the competition in the Indian market is much smaller.

4) The Indian market is in line with Xiaomi's product positioning

India belongs to the low-end market, and Xiaomi's products are mainly positioned at "low prices" and "high cost performance". The prices of the products are in line with the income level of the Indian people. At a certain price level, people are more willing to spend the same money to buy better products, which is also an important factor for Xiaomi's success in India.

Since entering the Indian market in 2014, Xiaomi has been competing with Samsung and finally defeated Samsung in the forth quarter of 2017, ranking first in the Indian market. From the fourth quarter of 2017 to the fourth quarter of 2019, Xiaomi has been number one in India for nine consecutive quarters. Although shipments and market share have slightly changed during the period, they have always maintained ahead, as shown in Figure 2.

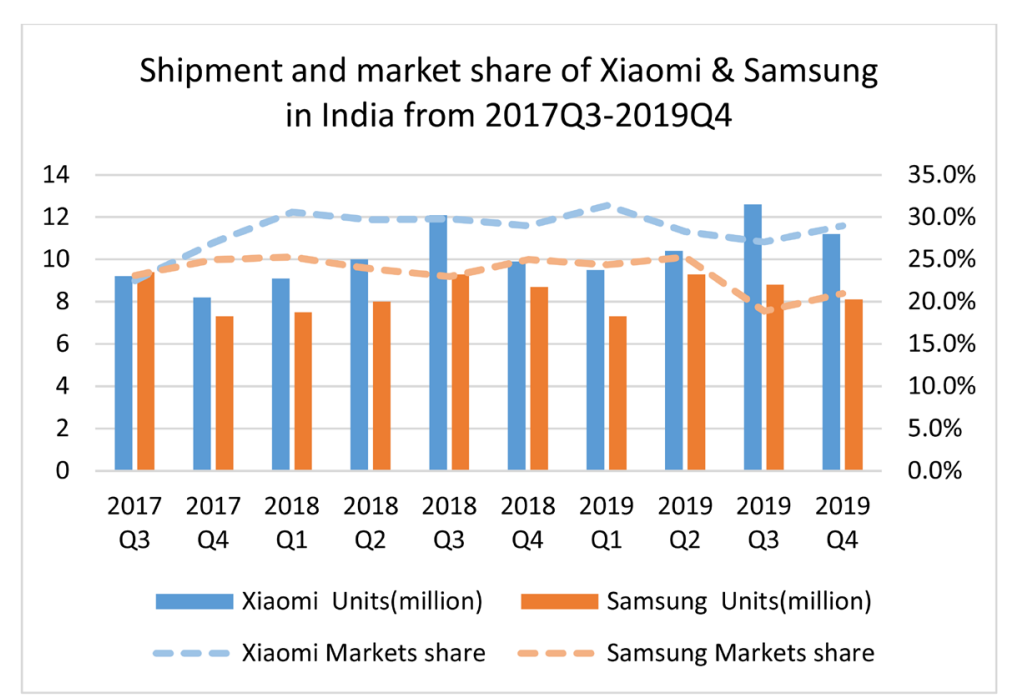

Data Source: Canalys \& IDC.

Figure 2. Shipment and market share of Xiaomi \& Samsung in India from 2017Q3-2019Q4. 


\subsection{Development Stage-European Market (2017-Present)}

After experiencing a huge setback in overseas development in 2016, after careful consideration, in 2017 Xiaomi turned to developed markets in Europe and the United States with a large number of internationally renowned brands of mobile phones. The Indian market is very important, but at this time Apple, Huawei and Samsung have established a firm foothold in the European market, and Xiaomi must also follow the pace of its competitors and enter the European market. Xiaomi is a technology-focused company. The reputation of high cost performance for Xiaomi stays in the mid-range market. Xiaomi wants to enter the high-end market, and the European market is a relatively mature high-end market (Liu, 2016). The sale of Xiaomi mobile phones in the European market is conducive to the brand influence of Xiaomi mobile phones.

With little difference in performance and quality, Xiaomi's high cost performance is the most popular no matter where it goes. Xiaomi has successfully entered the field of vision of Europeans, especially young people's attention to Xiaomi. After the Mi 6 series, the quality of Mi mobile phones has reached a new level. It has shown a brand image with high-end product characteristics in Europe, and the design concept is in line with the European simple and lively style. It is a perfect combination of quality and price, and is sought after by the European market.

It can also be seen from IDC data that in the past two years, after the shipment volume of Xiaomi mobile phones in the Indian market was close to the ceiling, the rapid growth from the European market is provoking the growth beam of Xiaomi's overseas market, thereby driving Xiaomi's global market shipments volume to keep increasing, as shown in Figure 3.

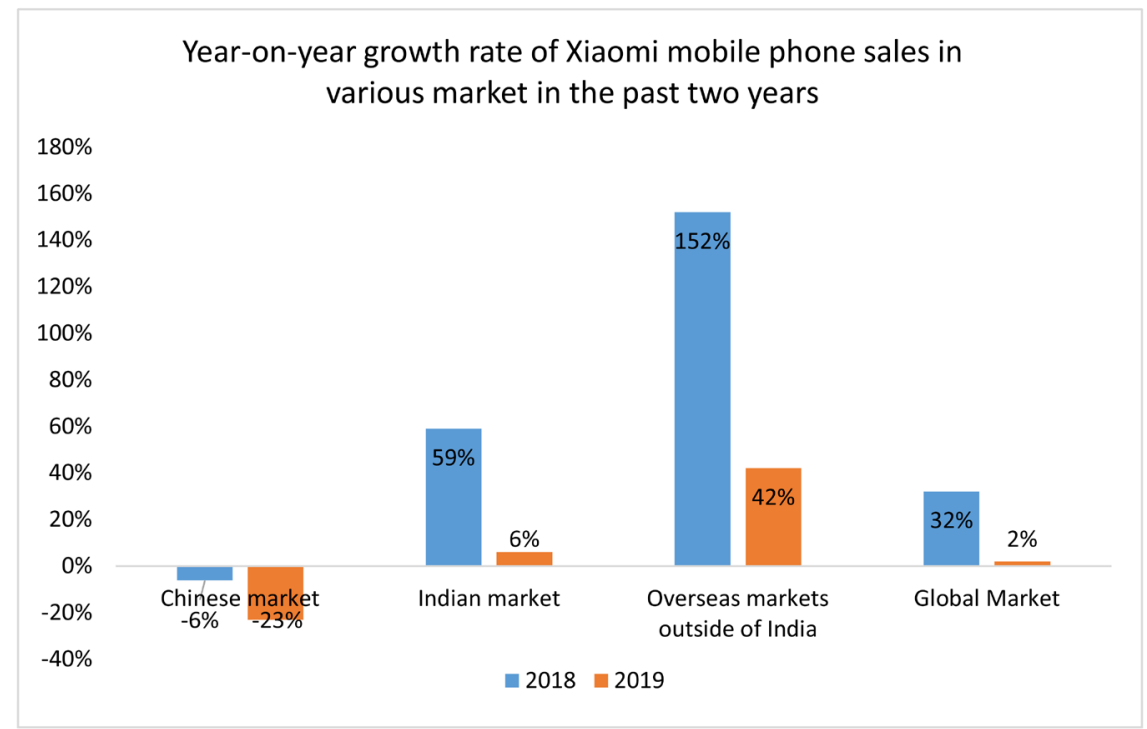

Data Source: IDC.

Figure 3. Year-on-year growth rate of Xiaomi mobile phone sales in various market in the past two years. 
From 2017 to 2019, in just three years, Xiaomi's market share in the European market exceeded 10\%, ranking fourth in the European market. Although the market share of Xiaomi still lags far behind the top three, Xiaomi's current entry time is relatively short, and the stamina is full. From Figure 4, it can be seen that Xiaomi has grown rapidly in Europe.

Xiaomi divides the European market into Western Europe and Eastern Europe. Western Europe mainly landed in Spain, Portugal and other countries. As of December 31, 2018, Xiaomi's mobile phone shipments in Western Europe increased by $415.2 \%$ year-on-year; in the fourth quarter of 2019, according to Canalys reports, Xiaomi achieved the fastest growth rate in many Western European countries. The highest growth rate was 206\%, ranking second in the Spanish market, and fourth in France and Italy, as shown in Table 3.

Xiaomi's development in the Eastern European market is also very rapid. In November 2017, Xiaomi opened 8 authorized stores in Ukraine and released Xiaomi MIX 2 locally on November 16. Thanks to the emphasis on fan culture, Xiaomi has built a good fan base in Ukraine. The local Xiaomi community in Ukraine, which was launched in August, now has more than 13,000 users and continues to grow. According to the report of Xiaomi in the fourth quarter of 2018, Xiaomi has surpassed Samsung with a 26.7\% market share, becoming the number one mobile phone sales brand in Ukraine. In Russia, in the first half of 2019 , the Xiaomi brand accounted for $22 \%$ of the online market and became the champion of online sales in Russia, which marked another breakthrough for Xiaomi in overseas markets.

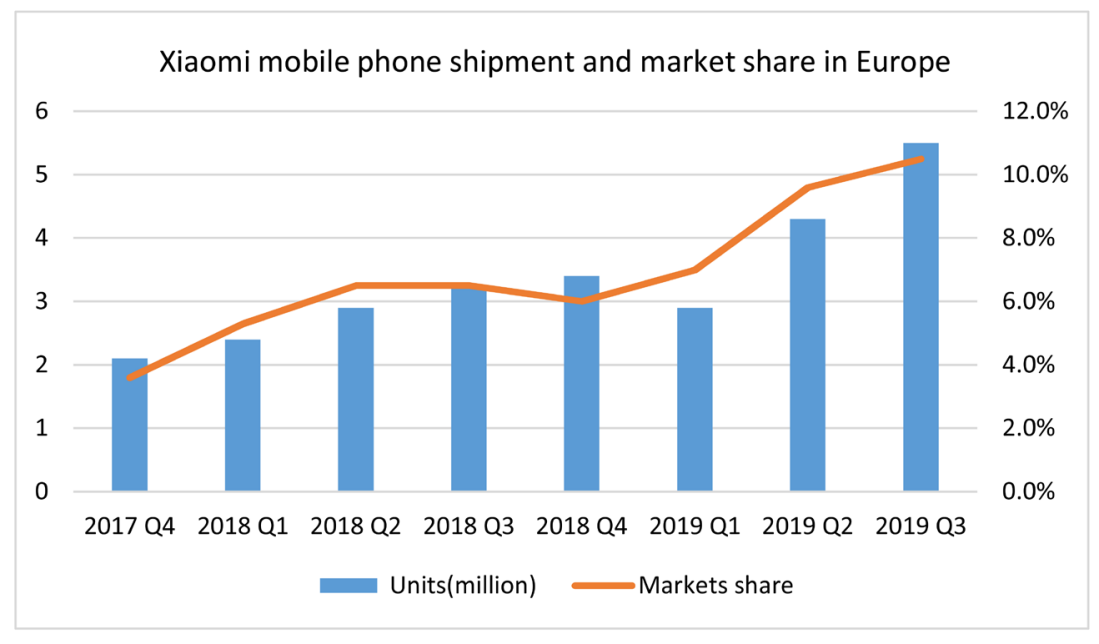

Data Source: Canalys.

Figure 4. Shipment and market share of Xiaomi mobile phones in Europe.

Table 3. Xiaomi's market share in Western Europe.

\begin{tabular}{cccccccc}
\hline & $2018 \mathrm{Q} 1$ & $2018 \mathrm{Q} 2$ & $2018 \mathrm{Q} 3$ & $2018 \mathrm{Q4}$ & $2019 \mathrm{Q1}$ & $2019 \mathrm{Q} 2$ & 2019 Q3 \\
\hline Market share & $2.2 \%$ & $3.5 \%$ & $3.7 \%$ & $3.2 \%$ & $4.6 \%$ & $5.5 \%$ & $7 \%$ \\
\hline
\end{tabular}

Data Source: Xiaomi's quarterly report. 


\section{Xiaomi's Overseas Market Entry Model and Marketing Strategy}

\subsection{The Entry Mode of Xiaomi's Overseas Market}

The market entry model can be divided into export model (indirect export and direct export), contract model (license model, franchise model, contract manufacturing model, management contract model and project contract model, two-way trade), investment model (sole proprietorship, Joint ventures) and international strategic alliances.

When Xiaomi entered the Indian and European markets, it adopts the export mode with less risk. Compared with other models, the export model is easier to achieve, with less investment in the target market, and once a risk occurs, the loss is smaller; at the same time, further measures can be taken at any time according to the sales situation in the target market.

Xiaomi's initial strategy in the Indian market was export first, copy the domestic innovative marketing concepts, and cooperating with India's largest local online retailer Flipkart for a limited-time "hunger marketing" to sell its products exclusively, which greatly improved Xiaomi's popularity in India in the short term (Ma, 2018). As Xiaomi's sales in India continue to increase and maintain its No. 1 market share, in India's long-term entry strategy, Xiaomi chose to improve its independent supply chain, build factories, open more experience stores and add direct sales model on the official e-commerce platform in the later stages, so as to deepen its influence on overseas markets and base itself on long-term development.

In the European market, Xiaomi adopts the mode of cooperating with local operators for distribution under the export model, which reduces entry barriers and accelerate the entry speed. After submitting the IPO in 2018, it reached an in-depth cooperation with the British telecom operator three; cooperated with $\mathrm{Li}$ Ka-shing's Yangtze River Hutchison to enter the European market. On the one hand, Xiaomi's smartphones, smart hardware and lifestyle products were introduced to Yangtze River Hutchison's Global telecommunications and retail departments; on the other hand, it will expand cooperation with CK Hutchison telecommunications stores in the European market (Kong, 2019).

\subsection{Xiaomi's Marketing Strategy in Overseas Markets}

\subsubsection{Price Strategy}

Xiaomi entered the Indian market, combined with local actual conditions and adopted a low-price strategy to allow more Indians to use high-quality smartphones with less money. In order to reduce costs, Xiaomi decided to build a factory locally. On the one hand, India's labor costs are relatively low, while the mobile phone manufacturing industry is a labor-intensive industry that requires a lot of manpower. The use of cheap local labor can greatly reduce production costs; on the other hand, local production can avoid high tariffs and reduce product costs. 
The reduced cost can reduce the selling price of mobile phones or increase its own profits, which is beneficial to Xiaomi.

For some relatively high-end markets such as Europe, Xiaomi first enters the market through a low-price strategy, attracting some consumers, especially young consumers, to buy their products with low prices and high cost performance; at the same time, it improves product quality, raises prices, and opens the door to the high-end market in Europe. At the beginning of 2019, Lei Jun, President of Xiaomi, announced that Redmi will be independent as a separate brand and no longer belong to Xiaomi, in order to get rid of the impression of "low price" in consumers' minds and formally enter the high-end market.

In different types of markets, selling different products and adopting different price strategies are also important factors for Xiaomi's success in overseas markets.

\subsubsection{Product Strategy}

For mobile phones in overseas markets, on the one hand, Xiaomi has increased its research and development efforts to improve product quality. By the third quarter of 2019, Xiaomi's R \& D expenses accounted for 3.8\%, an increase of $10.1 \%$ over the previous quarter; on the other hand, it will establish after-sales service points in various overseas markets to increase the satisfaction rate and repurchase rate of purchased customers.

In addition, as a technology company, Xiaomi implements the overall strategy of mobile phones + Alot products + Internet services, produces a variety of products such as mobile phones, bracelets, smart TVs, smart speakers and other products, and is committed to creating a smart life. Xiaomi also adopts a product diversification strategy for overseas markets and sells these products to overseas markets to contribute to Xiaomi's overseas revenue.

In 2019, Xiaomi became the largest smart wearable brand in China and the second largest in the world. It shipped 12.8 million wearable devices, of which 73.3\% were bracelets. Xiaomi's bracelets are still far ahead. In the first quarter of 2019, the wearable device market ranked first in shipments; in the third quarter of 2019 , the shipments reaching 12.2 million units, with a year-on-year increase of $74 \%$. Since the third quarter of 2015 , driven by strong domestic market performance and active overseas expansion strategies, Xiaomi's global market share has hit a new high of $27 \%$.

The sales performance of Xiaomi smart TV in overseas markets is also very good. In July 2018, Xiaomi won 56.6\% of the market share of Flipkart-India's largest TV website, and over $10 \%$ of the overall TV market in India. As of the fourth quarter of 2019, Xiaomi smart TV has maintained the first sales volume in India's smart TV market for seven consecutive quarters. In September 2018, Xiaomi TV entered Indonesia. As of June 30, 2019, Xiaomi's smart TV shipments reached the top five in the world.

Xiaomi's smart speaker "Xiao Ai" is not only a audio, but also can be interconnected with a series of Xiaomi products, providing users with a high-tech 
quality of life while increasing the sales of their various products. As of December 31,2018, the number of smart devices equipped with "Xiao Ai" and activated has exceeded 100 million, and the number of monthly active users of "Xiao Ai" has exceeded 38.8 million. At the same time, as of the end of February 2019, the cumulative shipments of smart speakers exceeded 9 million units. As can be seen from Figure 5, shipments in the last three quarters of 2018 increased significantly compared with the first quarter. Although in the fourth quarter of 2018, the market share dropped significantly, the shipments in the first quarter of 2019 and the market share has risen rapidly again, and basically maintains a global market share of more than $10 \%$, ranking among the top 5 in the world.

\subsubsection{Channel Strategy}

Xiaomi mainly adopts an export model in overseas markets. Basically all products are produced in China and sold abroad. However, the direct and indirect export model has the problems of weak control and low market closeness, which increases its transaction costs and transportation costs. Therefore, Xiaomi will give priority to overseas markets with moderate geographic distances.

In the long-term entry strategy of entering the international market, Xiaomi will choose to improve its own supply chain, build factories, open more experience stores and official e-commerce platform direct sales models to deepen its influence on overseas markets, and build on long-term development.

Xiaomi first entered the market through an online e-commerce platform direct sale, and opened offline stores in well-developed countries based on sales in different markets and combined with different types of Xiaomi products. There are three types of Xiaomi stores-Mi Home (experience store), Mi Preferences Partners (Xiaomi preferred partner store) and Mi Stores (in small towns), with a fairly complete offline sales channel. In India alone, there are more than 6000 stores, including more than $1790 \mathrm{Mi}$ Store stores focusing on second-tier cities and rural areas. In Europe, Xiaomi has opened more than 100 offline stores. The

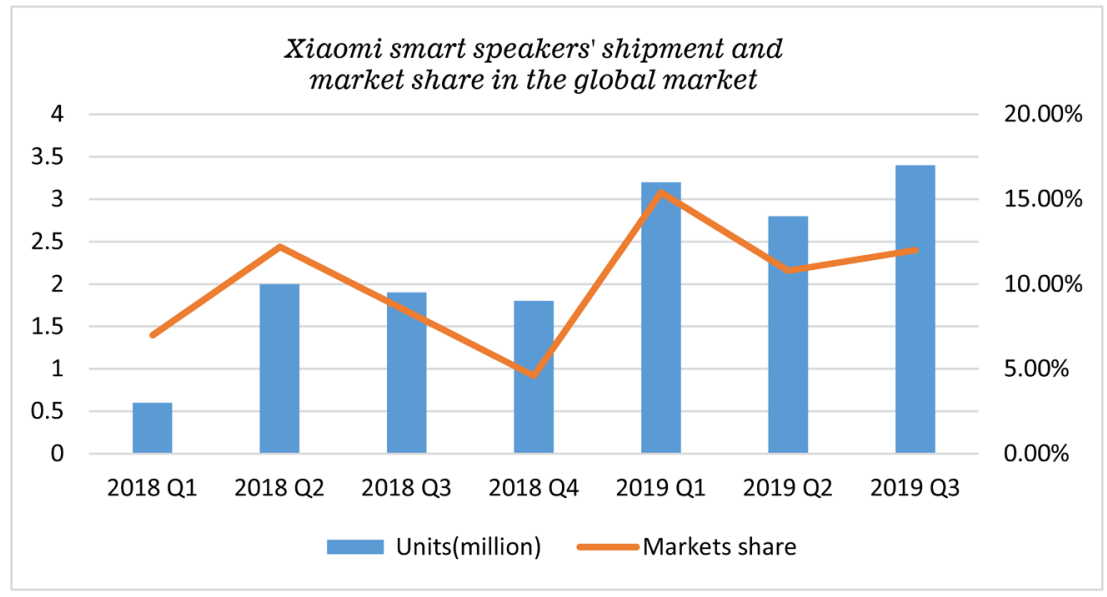

Data Source: Canalys.

Figure 5. Xiaomi smart speakers' shipment and market share in the global market. 
opening of Xiaomi Home has enabled more people to understand the performance of Xiaomi's products, and the number of fans of Xiaomi has increased, which has brought better growth momentum for Xiaomi's online sales.

In addition, for inexperienced markets, due to many related restrictions, Xiaomi cooperates with local operators for distribution, which reduces entry barriers and speeds up entry.

\subsubsection{Promotion Strategy}

While entering foreign markets, Xiaomi also brought its fan economy marketing into major overseas markets, striving to build a core and loyal customer group. At the beginning of 2019, Xiaomi launched a new e-commerce platform called ShareSave with three purchase modes: Pair-up (pairing), Drop (bargaining) and Kickstart (crowdfunding), because it firmly believes in the power of the community and Mi fans, ShareSave hopes that Xiaomi fans can connect with each other to enjoy and share the shopping experience. At the same time, ShareSave is also a test site for important markets, allowing Xiaomi to learn more about the needs of local consumers for various products.

In addition, in different regions, Xiaomi chooses different promotion methods. In India, Xiaomi chose to cooperate with the influential Bollywood celebrity Katrina Kaif and the popular Bollywood star Hrithik Roshan in line with the Xiaomi brand image. In Europe, Xiaomi has made great efforts in naming and advertising. The European consumer market is relatively mature and positioned as a mid-to-high-end market. In terms of naming strategy, Xiaomi chose to retain the most well-known Mi series naming blessing to strengthen the influence of its high-end flagship camp and enhance the brand recognition of its products in overseas markets. Combined with the strong artistic atmosphere of Europe, Xiaomi's advertisements highlight that photography works of art level can also be taken with mobile phones; capture the daily hobbies of a large number of young European consumers who love outdoor sports, and launch advertisements with anti-shake features on mobile phones, so that young people in Europe who love sports can quickly find emotional resonance.

\section{Summary of Xiaomi's Internationalization Experience and Its Enlightenment to Other Companies' Internationalization}

\subsection{Be Fully Prepared before Entering the International Market}

Xiaomi started to internationalize in 2014. Lei Jun once confidently said that Xiaomi would enter 10 countries including India, Russia and Brazil within one year, spanning Asia, Europe and America. However, in fact, Xiaomi's Internet marketing methods are not applicable in all regions, only the Indian market worked well at the time. In the Brazilian market, in addition to the blocking of online sales, it also encountered subsidy policies and other legal issues. Xiaomi withdrew from the market one year after announcing its entry into Brazil. As a result, the internationalization of Xiaomi in 2015-2016 caused heavy losses. Lei 
Jun later reflected: "Globalization cannot be radical." "Globalization has to be a long-term plan for 10 or 20 years. We should do each market one by one." Indeed, different countries and different markets have different political and economic systems and related laws and policies. Without a full understanding, evaluation and judgment of the market, it is very difficult and unwise to copy the domestic model and enter the new overseas market. After deciding to enter the international market, it is a necessary step to conduct market research, choose the right market and enter in the right way.

\subsection{Competition in the Domestic Market Is Fierce, So We Must Be Brave to Go Abroad and Seize the International Market}

Xiaomi's ability to enter the world's top 500 in nine years is largely due to Xiaomi's international vision. The income from overseas markets has made a huge contribution to Xiaomi's entry into the world's top 500. Xiaomi was established in 2010 and began to enter the international market in 2014, just catching up with the wave of India's replacement of functional phones with smartphones. Xiaomi seized this opportunity and took the lead in entering the Indian market, providing cost-effective products in the Indian market, gradually defeating Samsung and becoming the largest mobile phone seller in India. While taking into account the overseas market, Xiaomi develops its domestic business by doing a two-pronged approach. If only domestic competition is taken into consideration, it will be too late to transfer to foreign markets when domestic competition is severe. Therefore, companies must cultivate an international perspective, combine current national policies, such as the "One Belt One Road" policy, and find ways to open up new markets and seize opportunities to enter the international market in the face of fierce competition in the domestic market.

\subsection{Increase R \& D Investment and Improve Brand Quality}

If an enterprise wants to have long-term development, it must improve the quality and brand of its products in order to be recognized by more people and have greater development. As a technology company, Xiaomi chose to enter the Indian market in the initial stage and provide mid-to-low-end products. However, with the continuous development of Xiaomi, Xiaomi's investment in scientific research and innovation has been increasing. At the current stage, it mainly enters the European market, provides mid-to-high-end products to enhance their brand image. For technology companies, only by continuously improving product quality and brand reputation can they get more recognition and trust from people and gain a firm foothold in the international market.

\subsection{Focus on Intellectual Property Rights and Properly Solve Patent Disputes}

Patent issues are an inevitable problem for many Chinese companies, including Xiaomi, will encounter in their transnational development. In December 2014, 
Ericsson sued Xiaomi for patent infringement in India, demanding that "Xiaomi is prohibited from selling, promoting, manufacturing and importing relevant products suspected of infringing Ericsson's patents in the Indian market". Later, Xiaomi solved the dispute temporarily by obtaining a reverse license agreement from Qualcomm. However, this patent dispute has had a huge impact on Xiaomi's product sales and brand image (Zhao, 2016). In 2014, Xiaomi had only 151 patents, and in 2015 there were only 495 patents. Since then, Xiaomi has applied for and purchased a number of patents quickly: in 2016, it purchased 332 US patents from Intel and 1500 patents from Microsoft; In 2017, Xiaomi purchased patents from Nokia. As of April 2018, the number of authorized invention patents of Xiaomi in the past years was 1415, and the total number of patents was 14,491 . For multinational companies, product patents are not only a proof of their own strength, but also the best guarantee for their multinational operations.

\section{Conflicts of Interest}

The authors declare no conflicts of interest regarding the publication of this paper.

\section{References}

Kong, X. H. (2019). Research on the Marketing Strategy of Xiaomi's Entering the European Market. Shenyang: Liaoning University.

Liu, C. X. (2016). Western European Marketing Strategy Analysis of Domestic Mobile Phones. Guangzhou: Guangdong University of Foreign Studies.

Ma, J. J. (2018). Research on the International Business Model of Chinese Mobile Phone Companies. Wuhan: Huazhong University of Science and Technology.

Zhang, M. H. (2016). Research on Xiaomi's International Market Selection. Beijing: Beijing Institute of Technology.

Zhao, Y. (2016). A Case Study of Xiaomi's International Market Entry Mode. Dalian: Dalian University of Technology. 